\title{
Ginsenoside Rb1 protects PC12 cells against $\beta$-amyloid-induced cell injury
}

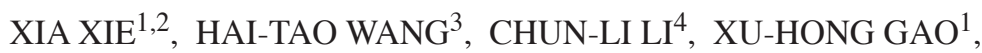 \\ JIN-LAN DING ${ }^{1}$, HAI-HUA ZHAO ${ }^{1}$ and YONG-LI LU ${ }^{1}$
}

\author{
${ }^{1}$ Department of Anatomy, Basic Medical Sciences College, China Medical University, Liaoning 110001; \\ ${ }^{2}$ Department of Anatomy, Medical College, Dalian University, Liaoning 116622; ${ }^{3}$ Department of Histology and Embryology, \\ North China Coal Medical University, Hebei 063000; ${ }^{4}$ Institute for Biomedical Sciences of Pain and Institute for \\ Functional Brain Disorders, Tangdu Hospital, Fourth Military Medical University, Shanxi 710038, P.R. China
}

Received February 5, 2010; Accepted April 19, 2010

DOI: $10.3892 / \mathrm{mmr} 00000308$

\begin{abstract}
Excessive accumulation of $\beta$-amyloid (A $\beta)$ has been proposed as a pivotal event in the pathogenesis of Alzheimer's disease. Possible mechanisms underlying $A \beta$-induced neuronal cytotoxicity include oxidative stress and apoptosis. Reactive oxygen species (ROS) have been proposed to be involved in the apoptotic mechanism of $A \beta$-induced cytotoxicity. Ginsenoside Rb1 (GRb1), which is among the key compounds of ginsenoside, found in ginseng, may be a potent scavenger of ROS. To examine the potential protective effect of GRb1 in $\mathrm{A} \beta_{25-35}$-induced cytotoxicity, cells were pre-treated with GRb1 for $24 \mathrm{~h}$, and then $A \beta_{25-35}$ was added to the medium for an additional $24 \mathrm{~h}$. Exposure to $A \beta$ led to the accumulation of ROS and lipid peroxidation, eventually causing a decrease in the Bcl-2/ Bax ratio, caspase-3 activation, cell apoptosis and cell death. Pre-treatment with GRb1 not only inhibited A $\beta$-induced ROS overproduction and lipid peroxidation, but also increased the Bcl-2/Bax ratio and attenuated caspase-3 activation, thereby improving cell survival. GRb1 may therefore act as a ROS scavenger, and such antioxidant properties may play a protective role against $A \beta$-induced cell injury. Further exploration of GRb1 antioxidant properties may provide novel therapeutic strategies for the treatment of Alzheimer's disease.
\end{abstract}

\section{Introduction}

Alzheimer's disease (AD) is the most common age-dependent neurodegenerative disorder $(1,2)$. Its major neuropathological features include senile plaques, neurofibrillary tangles and neuronal loss. $\beta$-amyloid $(\mathrm{A} \beta$ ) peptide, a 39-43 amino acid

Correspondence to: Professor Yong-Li Lu, Department of Anatomy, Basic Medical Sciences College, China Medical University, 92 North 2nd Road, Shenyang, Liaoning 110001, P.R. China

E-mail: 1yl1944428@yahoo.com.cn

Key words: amyloid, ginsenoside Rb1, oxidative stress, apoptosis $\beta$-sheet peptide, is the major protein component of senile plaques in the AD brain. The deposition and excessive accumulation of $\mathrm{A} \beta$ has been proposed as a pivotal event in the pathogenesis of $\operatorname{AD}(3,4)$, although the precise mechanism by which $A \beta$ induces neuronal death remains unclear. It is well established that $A \beta$ possesses neurotoxic activity, which has been associated with peptide self-aggregation and leads to the formation of amyloid-like fibrils, and eventually to neuronal death through apoptosis. Several studies suggest that oxidative stress is involved in an apoptotic mechanism by which excessive ROS production leads to neuronal apoptosis in neurodegenerative disorders, such as $A \beta$-induced neuronal apoptosis (5-7). $A \beta_{25-35}$ is a short $A \beta$ fragment that exhibits large $\beta$-sheet fibrils and retains the same neurotoxicity as the full-length peptide (8). In this study, $A \beta_{25-35}$ was selected as a model for full-length $A \beta$ to induce neuronal damage.

Ginsenoside Rb1 (GRb1), which is among the key active compounds of ginsenoside, found in ginseng, has exhibited beneficial effects on memory and learning by facilitating cholingergic function and increasing synaptophysin levels in the hippocampus (9). Recently, it was reported that GRb1 plays a role in neuronal protection in response to ischemia (10-12). GRb1 was reported to increase the expression of anti-apoptotic genes after transient cerebral ischemia in vivo. Previous studies have also suggested that GRbl may act as a scavenger of toxic species, such as glutamate and hydrogen peroxide $(13,14)$. Since oxidative stress is involved in neuronal apoptosis in $\mathrm{AD}$, this raises the possibility that GRb1 may play a role in cellular defense against oxidative stress and neuronal apoptosis induced by $\mathrm{A} \beta$. Taken together, these studies suggest that Rb1 may rescue or protect neurons from insult and is a pharmaceutical candidate for the treatment of AD. However, the protective effects of GRb1 on A $\beta$-induced neuronal apoptosis have yet to be reported.

We therefore chose to investigate the effects of GRb1 on $\mathrm{A} \beta_{25-35}$-induced neuronal apoptosis and its underlying mechanism. The rat pheochromocytoma cell line (PC12), a common model for neuronal functional studies, was used. Changes in the production of ROS and MDA, Bcl-2 family proteins and caspase- 3 activity were examined, and the effects of GRb1 
on $A \beta_{25-35}$-induced injury were reported. To the best of our knowledge, this is the first study to demonstrate that ginsenoside $\mathrm{Rb} 1$ protects neuron from oxidative stress-induced cell injury in $\mathrm{AD}$.

\section{Materials and methods}

Materials. $\mathrm{A} \beta_{25-35}, 3$-(4,5-dimethylthiazol-2-yl)-2,5-diphenyltetrazolium bromide (MTT) and propidium iodide (PI) were purchased from Sigma. RPMI-1640, fetal bovine serum and horse serum were purchased from Hyclone. Antibodies were purchased from Santa Cruz. The ROS detection kit was purchased from Beijing Applygen Technologies. GRb1 was purchased from China's National Institute for the Control of Pharmaceutical and Biological Products. SABC, DAB and MDA kits were purchased from Boster Biological Technology Ltd. (Wuhan, P.R. China). A $\beta_{25-35}$ was prepared in a $1 \mathrm{mM}$ stock solution in phosphate-buffered saline (PBS) at $-20^{\circ} \mathrm{C}$, and aggregated overnight at $37^{\circ} \mathrm{C}$ before use. The stock solution was then diluted to the desired concentrations.

Cell culture and treatment. PC12 cells were grown in RPMI1640 containing $10 \%$ heat-inactivated horse serum and 5\% fetal bovine serum at $37^{\circ} \mathrm{C}$ in a $5 \% \mathrm{CO}_{2}$ atmosphere. The medium was changed every other day and cells were plated at the appropriate density according to each experimental scale. To study the effects of GRb1 on $A \beta_{25-35}$-induced cell injury, cells were pre-incubated with GRb1 for $24 \mathrm{~h}$, and then $A \beta_{25-35}$ was added to the medium for an additional $24 \mathrm{~h}$. The experimental groups were: $\mathrm{A}$, control; $\mathrm{B}, 25 \mu \mathrm{M} \mathrm{A} \beta_{25-35} ; \mathrm{C}, 0.01 \mathrm{mM}$ $\mathrm{GRb} 1+25 \mu \mathrm{M} \mathrm{A} \beta_{25-35} ; \mathrm{D}, 0.1 \mathrm{mM} \mathrm{GRb} 1+25 \mu \mathrm{M} \mathrm{A} \beta_{25-35} ; \mathrm{E}$, $1 \mathrm{mM} \mathrm{GRb} 1+25 \mu \mathrm{M} \mathrm{A} \beta_{25-35}$. Following pre-treatment with GRb1 and treatment with $A \beta$, the cells were subjected to the MTT assay and flow cytometry analysis, the measurement of ROS and MDA, Western blotting and immunocytochemistry.

MTT assay. Cell viability was measured by a quantitative colorimetric assay with MTT, which shows the mitochondrial activity of living cells. PC12 cells in 96-well plates were incubated with $\mathrm{A} \beta_{25-35}$ for $24 \mathrm{~h}$. Subsequently, $0.5 \mathrm{mg} / \mathrm{ml}$ MTT was added to each well and cells were incubated for $4 \mathrm{~h}$ at $37^{\circ} \mathrm{C}$. After the medium containing MTT was removed, cells and dye crystals were lysed in $100 \mu \mathrm{l}$ DMSO by gentle agitation of the plate for $10 \mathrm{~min}$, and the absorbance was read at $490 \mathrm{~nm}$.

Flow cytometric analysis. To quantify the number of apoptotic cells, cells were harvested and washed twice with cold PBS. After fixation in $70 \%$ ethanol at $4^{\circ} \mathrm{C}$ overnight, the cells were centrifuged at $200 \mathrm{x}$ g for $10 \mathrm{~min}$ and resuspended in $100 \mu \mathrm{l}$ PBS containing $50 \mu \mathrm{g} / \mathrm{ml} \mathrm{RNase}$ A at $37^{\circ} \mathrm{C}$ for $30 \mathrm{~min}$. The cells were then incubated in $500 \mu \mathrm{l}$ PBS containing $50 \mu \mathrm{g} / \mathrm{ml}$ PI at $4^{\circ} \mathrm{C}$ for $1 \mathrm{~h}$ in the dark. The fluorescence of cells was measured with a FACScan flow cytometer.

Measurement of ROS. Determination of intracellular oxidant production in PC12 cells was based on the oxidation of DCFH-DA by intracellular ROS, resulting in the formation of the fluorescent compound 2',7'-dichlorofluorescin (DCF). Cells were incubated with $1 \mu \mathrm{g} / \mathrm{ml}$ 2',7'-DCFH-DA for $45 \mathrm{~min}$ at $37^{\circ} \mathrm{C}$. After the cells were washed twice with
PBS, DCF fluorescence was monitored with a Hitachi F-2000 Spectrofluorimeter (excitation, $485 \mathrm{~nm}$; emission, $538 \mathrm{~nm}$ ).

Measurement of MDA. MDA, an index of lipid peroxidation, was measured by a commercial assay using the thiobarbituric acid method. The measurement was based on the conjugation ability of MDA with thiobarbituric acid (TBA) to form a red product with a maximum absorbance of $532 \mathrm{~nm}$.

Western blot analysis. Cells were homogenized by standard procedures. Protein concentrations were determined using the Bradford protein assay. Proteins $(50 \mu \mathrm{g})$ were heated for $10 \mathrm{~min}$ at $95^{\circ} \mathrm{C}$ and loaded on to $12 \%$ SDS-PAGE, then transferred electrophoretically onto nitrocellulose membranes and blocked in 5\% non-fat milk for $2 \mathrm{~h}$ at $4^{\circ} \mathrm{C}$. The blots were then incubated with I antibody (anti-Bcl-2, 1:200; anti-Bax, 1:200; anti- $\beta$-actin, 1:1,000) overnight at $4^{\circ} \mathrm{C}$ and II antibody (HRP $\mathrm{IgG}, 1: 5,000)$ for $1 \mathrm{~h}$ at room temperature, then subjected to autoradiography (ECL reagents; Amersham Pharmacia Biotech, Buckinghamshire, UK). The optical density (OD) was analyzed by the Gel Image Analysis System (Tanon 2500R, Shanghai, P.R. China).

Immunocytochemistry. Evaluation of active caspase-3 expression was performed according to the protocol of the SABC immunocytochemistry kit. Briefly, the cell slices were fixed in $4 \%$ paraformaldehyde for $30 \mathrm{~min}$, then incubated with caspase-3 antibody (1:200) at $4^{\circ} \mathrm{C}$ overnight and with biotinylated secondary antibody for $10 \mathrm{~min}$. After being reacted with a streptavidin-biotin-peroxidase complex for $30 \mathrm{~min}$, immunoreactivity was determined by 3,3'-diaminobenzidine. To better appreciate negative nuclei, the slices were counterstained with hematoxylin. Negative control sections were stained in an identical fashion, with caspase-3 antibody omitted. The evaluation of positive cells was conducted by examining yellow or brown granules in the cytoplasm or nucleus.

Statistical analysis. Results are expressed as the means \pm standard error of the mean (SEM), and were analyzed using SPSS 13.0 software. Statistical significance was determined by one-way analysis of variance (ANOVA) followed by the Tukey test when appropriate. $\mathrm{P}<0.05$ was considered statistically significant.

\section{Results}

Effect of GRb1 on cell viability and apoptosis. After incubation with $25 \mu \mathrm{M} \mathrm{A} \beta_{25-35}$ for $24 \mathrm{~h}$, the cell viability of the PC12 cells was determined using the MTT assay. As shown in Fig. 1, 25 $\mu \mathrm{MA} \beta_{25-35}$ significantly decreased the cell viability compared to the control group $(\mathrm{P}<0.01)$. However, pre-treatment with different concentrations of GRb1 significantly increased the cell viability of $\mathrm{A} \beta_{25-35}$-treated $\mathrm{PC} 12$ cells in a dose-dependent manner $(\mathrm{P}<0.05)$. Further examination revealed that $A \beta_{25-35}$ induced a significant increase in the apoptosis rate, which was defined as the percentage of cells with subdiploid DNA content determined by flow cytometry. Similar to the preventive effects of GRbl on the cell death, GRb1 dose-dependently and significantly decreased apoptosis $(\mathrm{P}<0.05)$ (Fig. 2). 


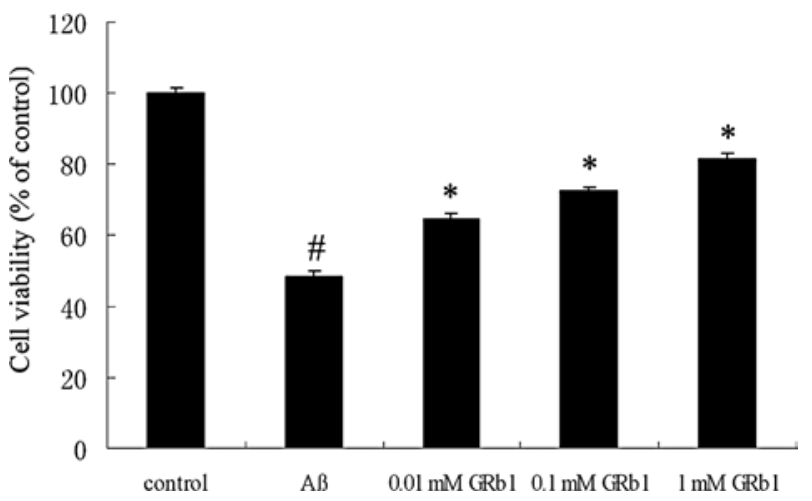

Figure 1. Effects of GRb1 on cell viability in $A \beta_{25-35}$-treated PC12 cells analyzed by the MTT assay. ${ }^{\text {}} \mathrm{P}<0.01$ compared to control group; ${ }^{*} \mathrm{P}<0.05$ compared to $\mathrm{A} \beta_{25-35}$ group.

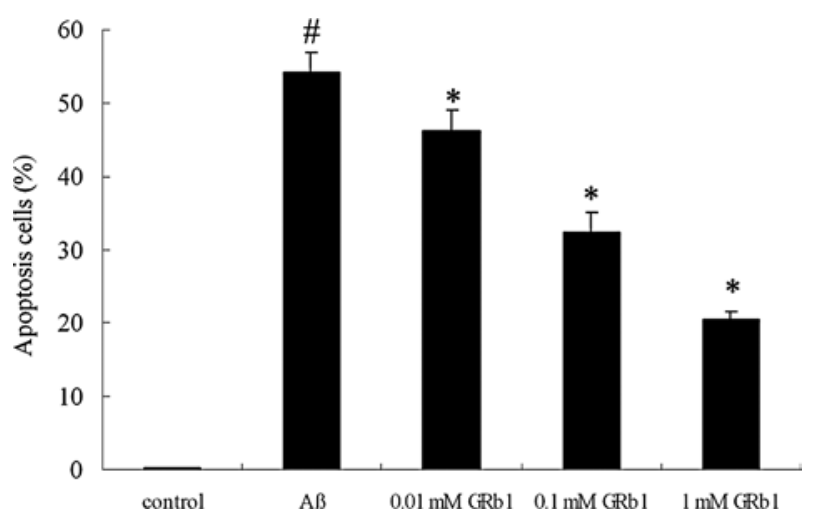

Figure 2. Effects of GRb1 on $A \beta_{25-35}$-induced cell apoptosis in PC12 cells analyzed by flow cytometric analysis. ${ }^{~} \mathrm{P}<0.01$ compared to control group; ${ }^{*} \mathrm{P}<0.05$ compared to $\mathrm{A} \beta_{25-35}$ group.

Effect of GRbl on oxidative stress in $A \beta_{25-35}$-treated PC12 cells. After $24 \mathrm{~h}$ of exposure to $\mathrm{A} \beta_{25-35}$, DCF fluorescence intensity in the $\mathrm{PC} 12$ cells was significantly increased compared to the control $(\mathrm{P}<0.01)$ (Fig. 3A). This increase in DCF fluorescence intensity was inhibited in a dose-dependent manner by pre-treatment with various concentrations of GRb1 $(\mathrm{P}<0.05)$.

Effect of GRbl on lipid peroxidation in A $\beta_{25-35}$-treated PC12 cells. After $24 \mathrm{~h}$ of exposure to $\mathrm{A} \beta_{25-35}$, an increase in the lipid peroxidation level of the PC12 cells of $200-250 \%$ compared to the contol was observed. This was indicated by the excessive formation of MDA in the cells (Fig. 3B). GRb1 pre-treatment significantly decreased the formation of MDA as compared to levels observed in the $A \beta_{25-35}$ group $(\mathrm{P}<0.05)$, but no significant difference was observed with different concentrations in the GRb1 group.

Effect of GRbl on the ratio of $B c l-2 / B a x$ in $A \beta_{25-35}$-treated PC12 cells. It is well known that the ratio of $\mathrm{Bcl}-2 / \mathrm{Bax}$ is regulated in response to cellular stress, including oxidative stress. We therefore examined the expression of Bcl-2 and Bax protein by Western blotting. After $24 \mathrm{~h}$ of exposure of the PC12 cells to $25 \mu \mathrm{M} \mathrm{A} \beta_{25-35}$, Bcl-2 expression was downregulated, while Bax expression was up-regulated. The ratio
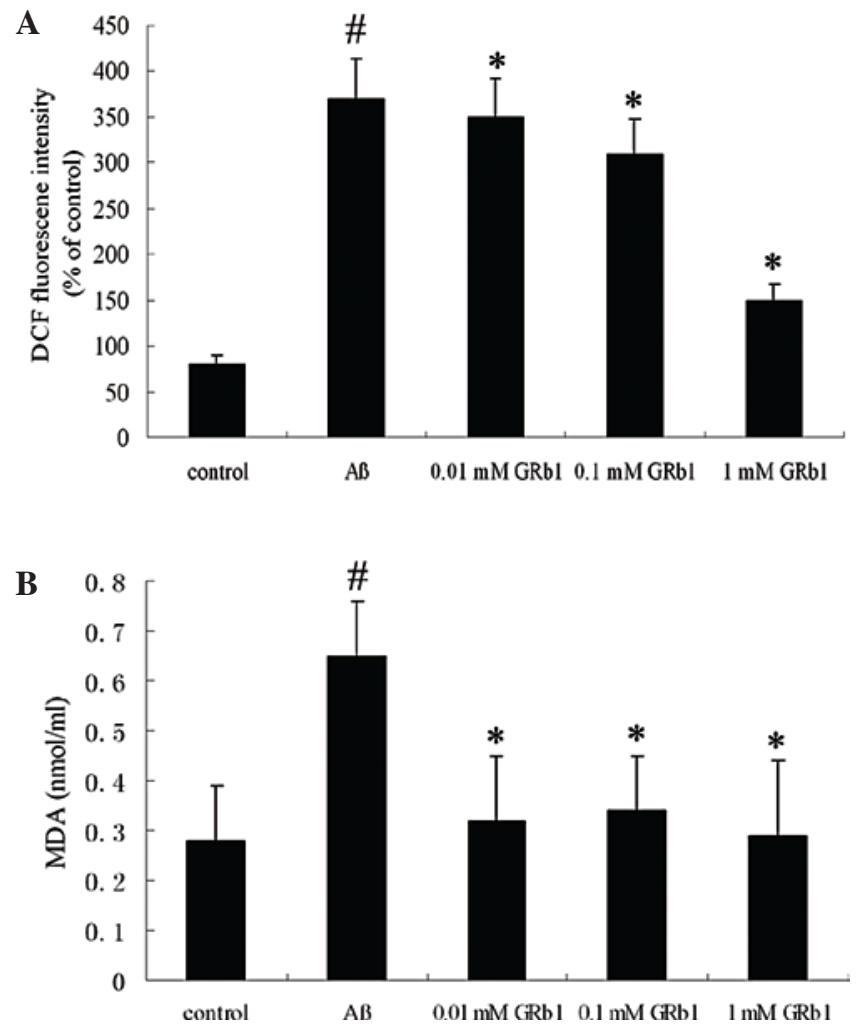

Figure 3. (A) Effects of GRb1 on ROS production in $\mathrm{A} \beta_{25-35}$-induced PC12 cells. ROS production was measured with the fluorescent dye DCFH-DA. (B) Effects of GRb1 on MDA production in $\mathrm{A} \beta_{25-35}$-treated $\mathrm{PC} 12$ cells. ${ }^{*} \mathrm{P}<0.01$ compared to control group; ${ }^{*} \mathrm{P}<0.05$ compared to $\mathrm{A} \beta_{25-35}$ group.

A

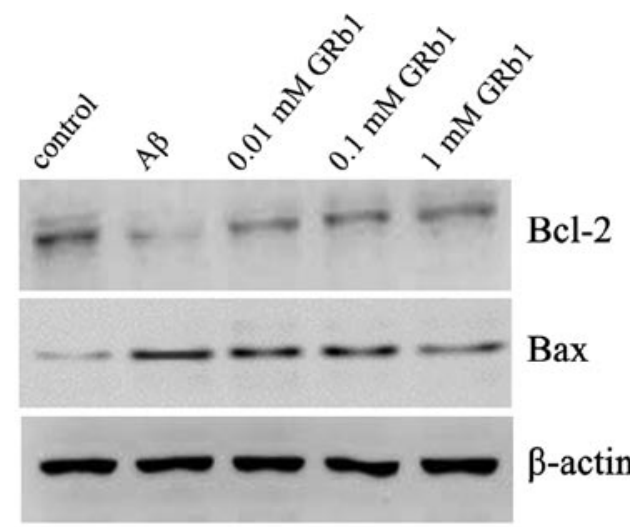

B

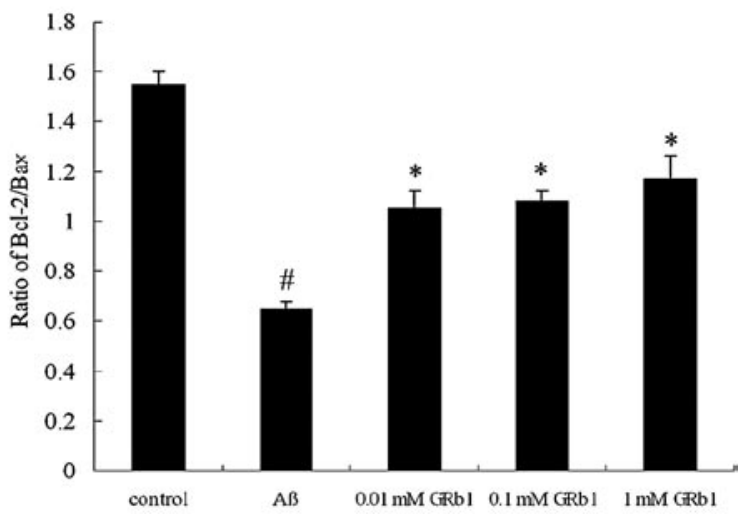

Figure 4. Effects of GRb1 on the expression of Bcl-2 and Bax in $\mathrm{A} \beta_{25-35^{-}}$ treated PC12 cells detected by Western blot analysis. (A) Representative immunoblot of $\mathrm{Bcl}-2$, Bax protein. (B) Ratio of $\mathrm{Bcl}-2 / \mathrm{Bax}$ proteins. ${ }^{~} \mathrm{P}<0.01$ compared to control group; ${ }^{*} \mathrm{P}<0.05$ compared to $\mathrm{A} \beta_{25-35}$ group. 

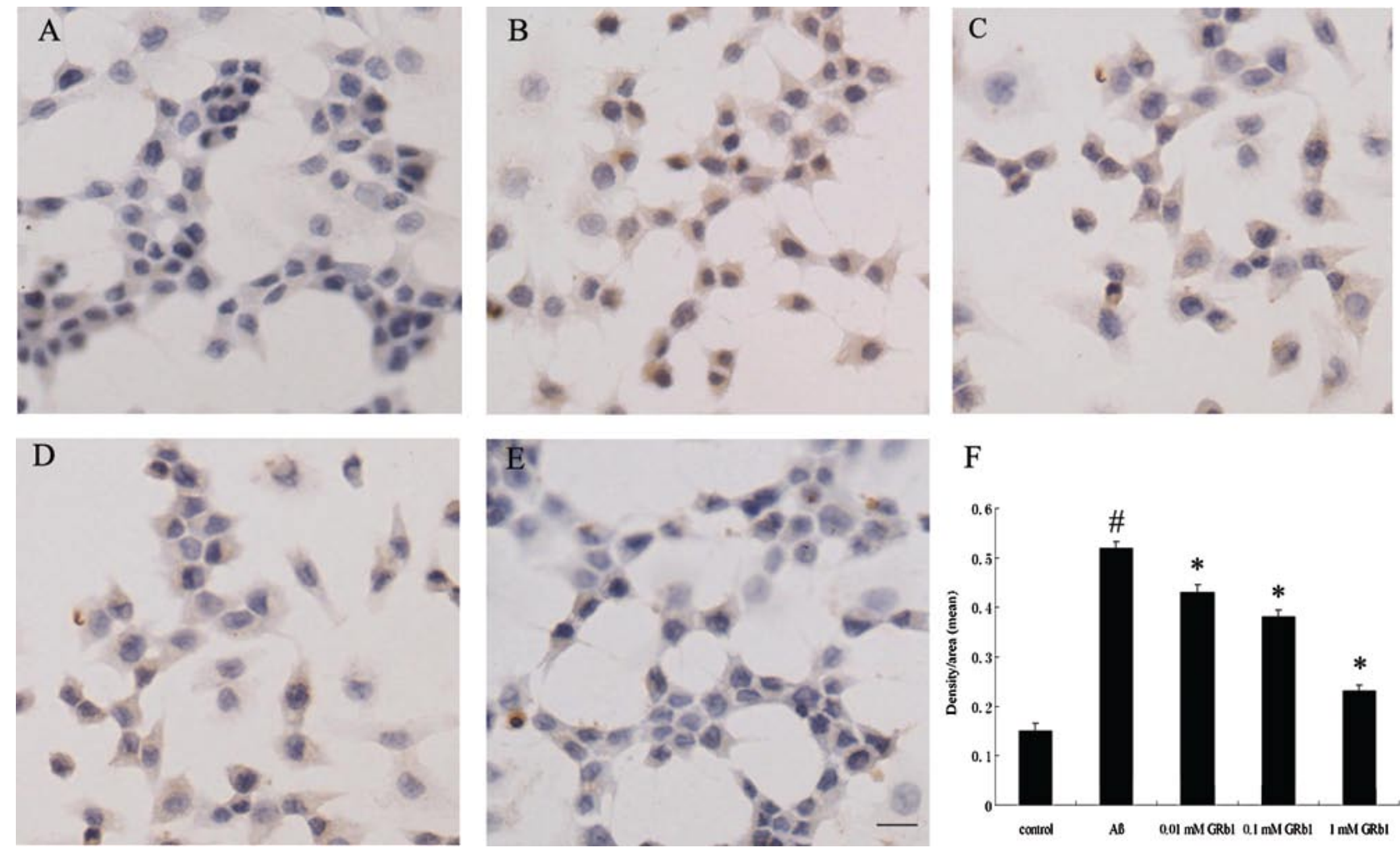

Figure 5. Effects of GRb1 on active caspase-3 expression in A $\beta_{25-35}$-treated PC12 cells analyzed by immunocytochemistry. (A), control; (B), $25 \mu \mathrm{M} \mathrm{A} \beta_{25-35}$ group; (C) $0.01 \mathrm{mM} \mathrm{GRb1}+25 \mu \mathrm{M} \mathrm{A} \beta_{25-35}$; (D) $0.1 \mathrm{mM} \mathrm{GRb1} \mathrm{A} \beta_{25-35}+25 \mu \mathrm{M}$; (E) $1 \mathrm{mM} \mathrm{GRb1}+25 \mu \mathrm{M} \mathrm{A} \beta_{25-35}$. Scale bar $10 \mu \mathrm{m}$. (F) quantification of immunocytochemistry. ${ }^{\#} \mathrm{P}<0.01$ compared to control group; " $\mathrm{P}<0.05$ compared to $\mathrm{A} \beta_{25-35}$ group.

of Bcl-2/Bax was decreased compared to the control (Fig. 4). In cells pre-treated with various concentrations of GRb1, Bcl-2 protein increased and Bax protein decreased compared to cells treated with $\mathrm{A} \beta_{25-35}$ alone. The ratio of Bcl-2/Bax protein increased compared to the $\mathrm{A} \beta_{25-35}$ group.

Effect of GRb1 on caspase-3 activity in A $\beta_{25-35}$-treated PC12 cells. Active caspase-3 is the final executor of apoptotic DNA damage, and its activity is a characteristic of apoptosis. Immunocytochemistry was used to determine the expression level of active caspase-3. Mixed nuclear-cytoplasmic immuno-positive neurons were evident in the $A \beta_{25-35}$ group. The protein expression level of active caspase- 3 was increased in the $A \beta_{25-35}$ group alone. By contrast, the protein expression level of active caspase-3 was decreased in PC12 cells treated with various concentrations of GRb1 (Fig. 5).

\section{Discussion}

In this study, $\mathrm{A} \beta$ treatment of $\mathrm{PC} 12$ cells induced oxidative stress and cell injury, accompanied by a significant increase in ROS production and lipid peroxidation, culminating in apoptotic cell death. These effects were prevented by GRb1 pre-treatment. Our data showed that GRb1 not only decreased $\mathrm{A} \beta$-induced overproduction of ROS and lipid peroxidation, but also attenuated $\mathrm{A} \beta$-induced cell apoptosis and cell death.

Ginseng root has been widely prescribed in China for thousands of years for a variety of ailments, particularly those associated with aging and memory deterioration. To date, more than 40 ginsenosides have been isolated from ginseng root and chemically identified. GRb1 (one protopanaxadiol type saponin) is one of the key active compounds of ginseng. GRb1 was recently found to play a role in neuronal cell protection against ischemic insult $(15,16)$. The mechanisms of GRb1 neuroprotection under ischemic stress may be related to the up-regulation of the anti-apoptotic protein expression of Bcl-2 and Bcl-xL and the down-regulation of the proapoptotic protein expression Bax, which inhibited apoptosis by preventing the release of cytochrome $c$. It is conceivable that GRb1 operates as a ROS scavenger, considering its properties in vitro against toxic reactive species, such as hydrogen peroxide and glutamate $(13,14)$. Since oxidative stress is involved in the neurodegenerative process of $\mathrm{AD}, \mathrm{GRb} 1$ may prevent the oxidative stress-induced neuronal apoptosis caused by $\mathrm{A} \beta$.

Oxidative stress reflects a situation in which ROS is continuously produced and exceeds the capacity of endogenous antioxidant defense systems. Several studies have suggested that oxidative stress plays a key role in $A \beta$-mediated neuronal cytotoxicity by triggering or facilitating neurodegeneration through a wide range of molecular events that eventually lead to neuronal cell loss (17-19). A $\beta$ significantly increases ROS production and enhances membrane lipid peroxidation, leading to neuronal apoptosis. It has been demonstrated that antioxidants have a beneficial effect in $A \beta$-induced neurotoxicity (20) and neurodegenerative disorders $(21,22)$. Therefore, in $\mathrm{AD}$, antioxidant therapies may delay the occurrence of apoptosis or prevent it altogether. In the present study, we showed that the presence of $A \beta$ not only increased ROS overproduction, but was also associated with lipid 
peroxidation in PC12 cells. These findings are consistent with the results of previous studies. Furthermore, GRb1 decreased ROS overproduction as well as lipid peroxidation in PC12 cells. Thus, the antioxidant properties of GRb1 may indeed provide a novel and effective neuroprotective approach against the oxidative injury induced by $A \beta$, particularly when considering that antioxidants attenuate $\mathrm{A} \beta$-induced oxidative injury.

In the present study, we found that $A \beta$ treatment not only induced the production of excess ROS, but also caused apoptosis and cell death in PC12 cells. Considering the strong correlation between A $\beta$-induced oxidative stress and cytotoxicity (17-19), ROS produced in mitochondria may leak to the cytoplasm, leading to oxidative stress and the initiation of apoptosis via the activation of apoptosis signaling (23). It is well established that the ratio of $\mathrm{Bcl}-2 / \mathrm{Bax}$ is crucial in the apoptosis of the mitochondrial pathway. Bcl-2 is a potent cell death suppressor, and its overexpression prevents cell death. However, Bax is a death-promoting factor, and its translocation to the mitochondrial membrane may lead to the loss of mitochondrial membrane potential and an increase in mitochondrial permeability. Increased mitochondrial permeability results in the egress of cytochrome $c$ from the mitochondria and the subsequent activation of procaspase-3 to caspase-3, which eventually leads to apoptosis $(24,25)$. We found that $\mathrm{A} \beta$ treatment significantly decreased the $\mathrm{Bcl}-2 / \mathrm{Bax}$ protein expression ratio and increased caspase-3 activity, in agreement with previous reports. Concurrently, we measured the effects of GRb1 on this process to clarify its neuroprotective mechanism. Our results indicate that GRb1 significantly increased the $\mathrm{Bcl}-2 / \mathrm{Bax}$ ratio and decreased caspase- 3 activity induced by $A \beta$, suggesting that GRb1 is capable of decreasing A $\beta$-induced apoptosis. Based on these findings, we postulate that the anti-apoptotic effect of GRb1 may be mediated by its antioxidant properties.

In conclusion, our data show that exposure to $A \beta$ leads to the accumulation of ROS and lipid peroxidation, eventually leading to a decrease in the $\mathrm{Bcl}-2 / \mathrm{Bax}$ ratio, subsequent caspase-3 activation, cell apoptosis and cell death. However, GRb1 was found to not only inhibit $A \beta$-induced ROS overproduction and lipid peroxidation, but also to increase the $\mathrm{Bcl}-2 / \mathrm{Bax}$ ratio and attenuate caspase-3 activation, thereby improving cell survival. GRb1 may therefore act as a ROS scavenger, and such antioxidant properties may play a protective role against $\mathrm{A} \beta$-induced cell injury. Further exploration of GRb1 antioxidant properties may provide novel therapeutic approaches aimed at preventing or palliating the consequences of $\mathrm{AD}$.

\section{References}

1. Forman MS, Trojanowski JQ and Lee VM: Neurodegenerative diseases: a decade of discoveries paves the way for therapeutic breakthroughs. Nat Med 10: 1055-1063, 2004.

2. Nordberg A: PET imaging of amyloid in Alzheimer's disease. Lancet Neurol 3: 519-527, 2004.

3. Hardy J and Selkoe DJ: The amyloid hypothesis of Alzheimer's disease: progress and problems on the road to therapeutics. Science 297: 353-356, 2002.

4. Zheng WH, Bastianetto S, Mennicken F, Ma W and Kar S: Amyloid-beta peptide induces tau phosphorylation and loss of cholinergic neurons in rat primary septal cultures. Neuroscience 115: 201-211, 2002.
5. Fukui K, Takatsu, H, Shinkai T, Suzuki S, Abe K and Urano S: Appearance of amyloid beta-like substances and delayed-type apoptosis in rat hippocampus CA1 region through aging and oxidative stress. J Alzheimers Dis 8: 299-309, 2005.

6. Kadowaki H, Nishitoh H, Urano F, Sadamitsu C, Matsuzawa A, Takeda K, Masutani H, Yodoi J, Urano Y, Nagano T and Ichijo H: Amyloid beta induces neuronal cell death through ROS-mediated ASK1 activation. Cell Death Differ 12: 19-24, 2005.

7. Li MH, Jang JH, Sun B and Surh YJ: Protective effects of oligomers of grape seed polyphenols against beta-amyloidinduced oxidative cell death. Ann NY Acad Sci 1030: 317-329, 2004.

8. Iverson LL, Mortishire-Smith RJ, Pollack SJ and Shearman MS: The toxicity in vitro of beta-amyloid protein. Biochem J 311: $1-16,1995$.

9. Inhee MJ, Hong HS, Boo JH, Lee KH, Yun SH, Cheong MY, Joo I, Huh K and Jung MW: Ginsenoside Rb1 and Rg1 improve spatial learning and increase hippocampal synaptophysin level in mice. J Neurosci Res 63: 509-515, 2001.

10. Fujita K, Hakubaa N, Morizane HR, Yoshida T, Shudou M, Sakanaka M and Gyoa K: Ginsenoside Rbl protects against damage to the spiral ganglion cells after cochlear ischemia. Neurosci Lett 415: 113-117, 2007.

11. Sakanaka M, Zhu P, Zhang B, Wen TC, Cao F, Ma YJ, Samukawa K, Mitsuda N, Tanaka J, Kuramoto M, Uno H and Hata R: Intravenous infusion of dihydroginsenoside Rb1 prevents compressive spinal cord injury and ischemic brain damage through upregulation of VEGF and Bcl-XL. J Neurotrauma 24: 1037-1054, 2007.

12. Yuan QL, Yang CX, Xu P, Gao XQ, Deng L, Chen P, Sun ZL and Chen QY: Neuroprotective effects of ginsenoside Rb1 on transient cerebral ischemia in rats. Brain Res 1167: 1-12, 2007.

13. Liu M and Zhang JT: Effects of ginsenosides Rb1 and Rg1 on synaptosomal free calcium level, ATPase and calmodulin in rat hippocampus. Chin Med J 108: 544-547, 1995.

14. Liao B, Newmark H and Zhou R: Neuroprotective effects of ginseng total saponins and ginsenosides Rb1 and Rg1 on spinal cord neurons in vitro. Exp Neurol 173: 224-234, 2002.

15. Sun K, Wang CS, Guo J, Horie Y, Fang SP, Wang F, Liu YY, Liu LY, Yang JY, Fan JY and Han JY: Protective effects of ginsenoside Rb1, ginsenoside Rg1 and notoginsenoside R1 on lipopolysaccharide-induced microcirculatory disturbance in rat mesentery. Life Sci 81: 509-518, 2007.

16. Zhang B, Hata R, Zhu P, Sato K, Wen TC and Yang L: Prevention of ischemic neuronal death by intravenous infusion of a ginseng saponin, ginsenoside $\mathrm{Rb}(1)$, that upregulates $\mathrm{Bcl}-\mathrm{x}(\mathrm{L})$ expression. J Cereb Blood Flow Metab 26: 708-721, 2006.

17. Behl C, Davis JB, Lesley R and Schubert D: Hydrogen peroxide mediates amyloid beta protein toxicity. Cell 77: 817-827, 1994.

18. Butterfield DA, Castegna A, Lauderback CM and Drake J: Evidence that amyloid beta-peptide-induced lipid peroxidation and its sequelae in Alzheimer's disease brain contribute to neuronal death. Neurobiol Aging 5: 655-664, 2002.

19. Hensley K, Carney J, Hall N, Shaw W and Butterfield DA: Electron paramagnetic resonance investigations of free radicalinduced alterations in neocortical synaptosomal membrane protein infrastructure. Free Radic Biol Med 17: 321-331, 1994.

20. Koh SH, Noh MY and Kim SH: Amyloid-beta-induced neurotoxicity is reduced by inhibition of glycogen synthase kinase-3. Brain Res 1188: 254-262, 2008.

21. Floyd RA: Antioxidants, oxidative stress and degenerative neurological disorders. Proc Soc Exp Biol Med 222: 236-245, 1999.

22. Calabrese V, Cornelius C, Mancuso C, Barone E, Calafato S, Bates T, Rizzarelli E and Kostova AT: Vitagenes, dietary antioxidants and neuroprotection in neurodegenerative diseases. Front Biosci 14: 376-397, 2009.

23. Budihardjo I, Oliver $H$, Lutter $M$, Luo $X$ and Wang $X$ : Biochemical pathways of caspase activation during apoptosis. Annu Rev Cell Dev Biol 15: 269-290, 1999.

24. Tsujimoto Y and Croce CM: Analysis of the structure, transcripts, and protein products of $\mathrm{Bcl}-2$, the gene involved in human follicular lymphoma. Proc Natl Acad Sci USA 83: 5214-5218, 1986.

25. Chinnaiyan AM and Dixit VM: The cell-death machine. Curr Biol 6: 555-562, 1996. 